\title{
THE DISTRIBUTION AND CHEMICAL COMPOSITION OF ULTRACENTRIFUGALLY SEPARATED LIPOPROTEINS IN HUMAN SERUM
}

\author{
By RICHARD J. HAVEL, HOWARD A. EDER, AND JOSEPH H. BRAGDON \\ (From the Laboratory of Metabolism, National Heart Institute, National Institutes of Health, \\ Department of Health, Education, and Welfare, Bethesda, Md.)
}

(Submitted for publication January 17, 1955 ; accepted April 13, 1955)

In the past few years several methods have been developed for the analysis of serum lipoproteins. Lindgren, Elliott, and Gofman (1) have utilized the relatively low density of the lipoproteins to separate them from the other serum proteins by ultracentrifugal flotation. Quantitation was subsequently performed by refractometric methods in the analytical ultracentrifuge. Separations of lipoproteins have also been made by Cohn fractionation in cold ethanol, and the quantities of lipoprotein have been estimated from the lipid. content of the fractions $(2,3)$. Widely used at the present time is the method of zone electrophoresis with quantitation either by staining (4) or by chemical analysis of eluates from the supporting medium $(5,6)$.

Each of these methods has serious limitations. Analytical ultracentrifugal techniques $(7,8)$ require the possession of expensive equipment. The quantitation of data is subject to considerable error and gives no information regarding the chemical composition of the lipoproteins. Cohn fractionation requires facilities for operation at $-5^{\circ} \mathrm{C}$. It permits accurate determination of the lipid components of the alpha and beta lipoproteins, but with this technique it is impossible to subfractionate these groups. With certain abnormal sera the method is unreliable (9). Determination of electrophoretically separated fractions by staining techniques or by chemical analysis of eluates is subject to appreciable error. Both Cohn fractionation and electrophoretic techniques fail to separate lipoproteins from other serum proteins, thus making impossible the study of the protein moiety.

The combination of preparative ultracentrifugation with chemical analysis of the separated fractions would seem to be a procedure by which both the distribution and composition of lipoproteins could be determined simply and accu- rately. Such a procedure was described by Turner, Snavely, Goldwater, Randolph, Sprague, and Unglaub (10). Under their conditions of ultracentrifugation, however, separation of discrete lipoproteins did not occur and their results are difficult to interpret. In the present study, lipoproteins have been separated from serum by repeated ultracentrifugations after progressively raising the solvent density. The separated fractions have been analyzed for total cholesterol, lipid phosphorus, and protein. The method has proved reliable and is, in our opinion, the simplest available procedure for the accurate quantitation of serum lipoproteins.

\section{METHODS}

The density of serum was raised by the addition of concentrated salt solution. The stock salt solution contained $153.0 \mathrm{gm}$. sodium chloride and $354.0 \mathrm{gm}$. potassium bromide per liter (density: 1.346). Solutions of lower density were prepared by dilution of the stock solution with $0.15 \mathrm{M}$ sodium chloride solution (density: 1.005) according to the formula :

$$
\mathrm{A} \times 1.005+\mathrm{B} \times 1.346=(\mathrm{A}+\mathrm{B}) \mathrm{X},
$$

where $\mathrm{A}$ is the volume of $0.15 \mathrm{M}$ saline, $\mathrm{B}$ the volume of stock solution, and $\mathrm{X}$ the desired density of the mixture. The density of serum or of infranates was raised to the desired non-protein solvent density by the addition of a salt solution according to a similar formula :

$$
A \times Y+B \times Z=(A+B) X
$$

TABLE I

Preparation of samples of known solvent density for

\begin{tabular}{|c|c|c|c|c|}
\hline \multicolumn{2}{|c|}{ serce } & \multicolumn{2}{|c|}{ Sealt salution } & \multirow{2}{*}{$\begin{array}{l}\text { Minal } \\
\text { Solvent Dene1 ty } \\
\text { of ienture }\end{array}$} \\
\hline $\begin{array}{l}\text { 8alvent } \\
\text { Derast ty }\end{array}$ & $\underset{\text { (II) }}{\text { Vall }}$ & Deneity & $\begin{array}{l}\text { volume } \\
\text { (II) }\end{array}$ & \\
\hline 1.006 & 10 & 2.346 & 2 & 1.063 \\
\hline 2.006 & 20 & 1.085 & 2 & 1.019 \\
\hline 1.029 & 9 & 1.200 & 3 & 1.004 \\
\hline
\end{tabular}
preparative ultracentrifugation 
TABLE II

Distribution and composition of lipoproteins in fractions of human serum separated at density 1.063

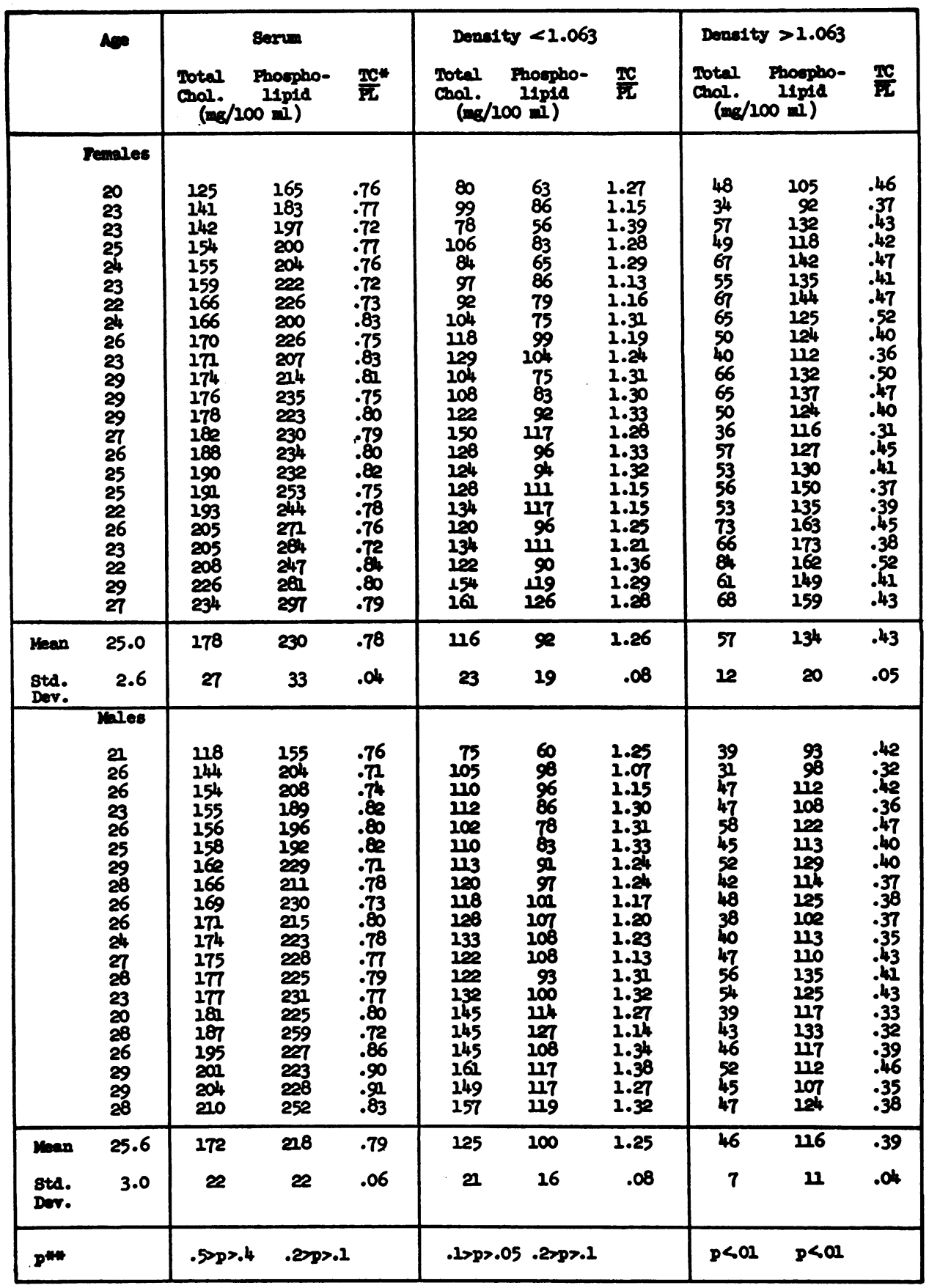

* Ratio total cholesterol to phospholipid.

$\dagger$ Std. Dev. $=\sqrt{\frac{\epsilon(x-\bar{x})^{2}}{n-1}}$.

** Probability that difference between mean values for males and females is due to chance. 
where $\mathbf{A}$ is the volume of serum or serum infranate, $B$ the volume of salt solution, $Y$ the non-protein solvent density of the sample whose density is to be raised (for serum, this is 1.006$), Z$ the density of the salt solution, and $\mathrm{X}$ the non-protein solvent density of the mixture. In Table $I$ are listed the dilutions used in these experiments.

Ultracentrifugation was carried out in the 40 rotor of a Spinco preparative ultracentrifuge (Model L). Eight to $10 \mathrm{ml}$. of serum were delivered into a capped, plastic tube from a calibrated syringe. The appropriate volume of salt solution was added and the tube filled with a small amount of salt solution of the same density as the mixture. After centrifugation at $105,000 \times$ G. for 20 to 22 hours at 12 to $15^{\circ} \mathrm{C}$., lipoproteins of less than solvent density were concentrated in a layer at the top of the tube. Beneath this was a clear, colorless region occupying approximately one-fourth of the length of the tube; the remainder of the serum was stratified below the clear zone. The tube was placed in a tube-slicing device similar to that described by Randolph and Ryan (11) and sliced in the middle of the clear zone. The supernatant contents were transferred quantitatively with washings of $0.15 \mathrm{M}$ sodium chloride solution to a $5 \mathrm{ml}$. volumetric flask. The infranate was similarly transferred to a $10 \mathrm{ml}$. volumetric flask with washings of salt solution of equivalent density. If further separa- tion was to be carried out, additional salt solution was added to an aliquot of the infranate and centrifugation was repeated. In this way it is possible to separate several lipoprotein fractions from the same serum sample.1

Aliquots of the supernate(s), final infranate, and the original serum were extracted in ethanol-acetone $(1: 1)$ and analyzed for total cholesterol by the Sperry-Schoenheimer method (12) and lipid phosphorus by a modification of the method of Stewart and Hendry (13). Lipid phosphorus was converted to phospholipid by the factor 25. In some instances protein content of the ethanolacetone insoluble material was determined by a modification of the biuret method (14). The insoluble material was washed twice in ethanol-acetone, dried, and dissolved in an amount of sodium hydroxide solution equivalent to that contained in the usual biuret reagent. Biuret reagent without alkali was then added to the alkaline protein solution for color development.

\section{Subjects}

Forty-three men and women aged 20 to 30 were studied. They were physicians, nurses, and laboratory

1 Recent studies indicate that the 40.3 preparative rotor is more efficient for these purposes. It requires a small sample of serum ( 4 to $5 \mathrm{ml}$.) and the time of centrifugation can be reduced to 16 hours.

TABLE III

Distribution and composition of lipoproteins in fractions of human serum separated at densities 1.019 and 1.063

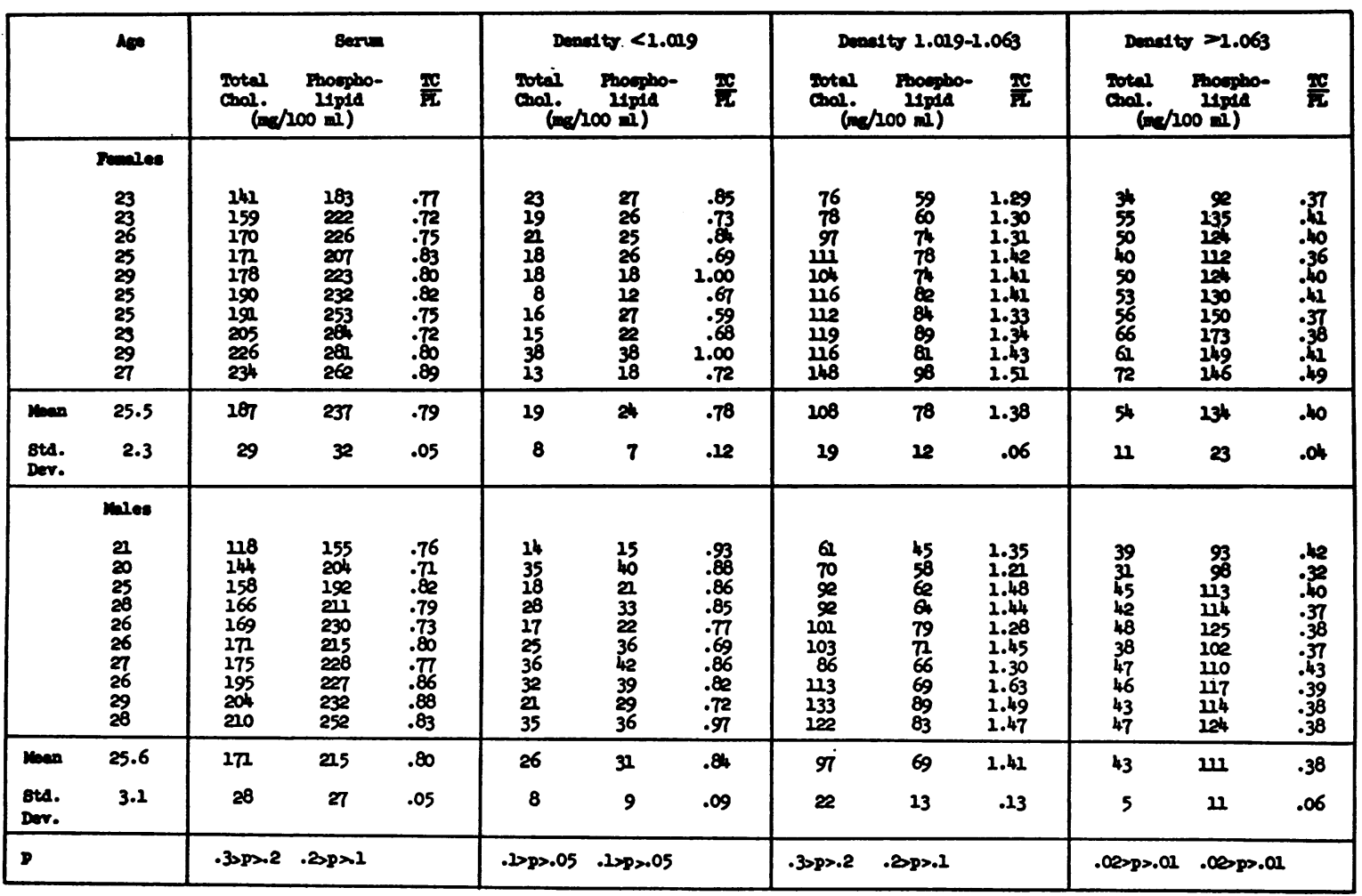


personnel. Individuals with known disease were excluded from this group. In addition, sera from several individuals with known disorders of lipid metabolism as well as a variety of animal sera were examined. Blood samples from humans were drawn following an overnight fast or a fat-free breakfast. Pooled serum obtained from the American Red Cross blood donor service was used for detailed analysis of high density lipoproteins.

\section{RESULTS}

\section{Young adult humans}

In Table II it can be seen that ultracentrifugation of serum at density 1.063 separates the lipoproteins into two components differing markedly in composition. Roughly 70 per cent of the total cholesterol and 50 per cent of the phospholipid are in the fraction having a density less than 1.063. When analyzed by paper electrophoresis the low density $(\mathrm{D}<1.063)$ lipoproteins have the mobility of beta lipoprotein and the high density (D > 1.063) lipoproteins that of alpha lipoprotein. Although the concentrations of serum total cholesterol and phospholipid are similar in young men and women in this series, men have more lipid in the $\mathrm{D}<1.063$ fraction, and women more in the $D>1.063$ fraction. Subfractionation of the $\mathrm{D}<1.063$ fraction reveals that there is more lipid in the lowest density fraction $(D<1.019)$ in males (Table III). This occurs despite the fact that in this smaller group the serum total cholesterol and phospholipid concentrations are appreciably higher in the females. This difference is also apparent to some degree in the intermediate fraction (D 1.019-1.063). The ratio of total cholesterol to phospholipid in the fractions is similar in both sexes. It can be seen that the ratio in the $\mathrm{D}<1.019$ fraction is similar to that of whole serum, whereas that in the D 1.0191.063 fraction is higher and that in the $D>1.063$ fraction is much lower.

For both fractionation procedures in these groups recovery of total cholesterol and phospholipid in the fractions ranged from 94 to 106 per cent of the serum value; recovery averaged 98 per cent for total cholesterol and 99 per cent for phospholipid. In order to test the reproducibility of the method, a sample of pooled human serum was fractionated in triplicate using the second fractionation procedure. Duplicate analyses for total cholesterol and phospholipid and single analyses

TABLE IV

Distribution and composition of lipoproteins in various disease states in humans

\begin{tabular}{|c|c|c|c|c|c|c|c|c|c|c|c|c|c|c|c|}
\hline \multirow{3}{*}{$\frac{\operatorname{mox}_{200}^{\infty}}{20-30}$} & \multirow{3}{*}{ 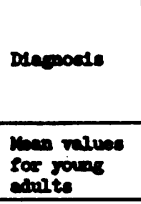 } & \multicolumn{3}{|c|}{ seren } & \multicolumn{4}{|c|}{ Denosty <1.019 } & \multicolumn{4}{|c|}{ Denad ty 2.029-1.063 } & \multicolumn{3}{|c|}{ Deast ty >1.063 } \\
\hline & & \multicolumn{2}{|c|}{ 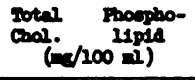 } & \multirow{2}{*}{$\frac{\frac{2 c}{85}}{.79}$} & \multirow{2}{*}{$\frac{\text { notal }}{\text { coll. }}$} & 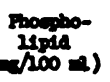 & \multirow{2}{*}{$\begin{array}{c}\text { reo- } \\
\text { tolin } \\
17\end{array}$} & \multirow{2}{*}{$\frac{\frac{20}{56}}{.82}$} & \multirow{2}{*}{$\begin{array}{c}\text { sotel } \\
\text { coll. }\end{array}$} & \multirow[t]{2}{*}{ 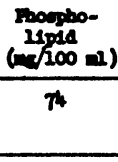 } & \multicolumn{2}{|l|}{ Pro- } & \multicolumn{2}{|c|}{ 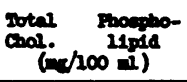 } & \multirow{2}{*}{$\frac{\frac{T C}{\mathrm{EL}}}{.40}$} \\
\hline & & 179 & 226 & & & 26 & & & & & 60 & 1.39 & 49 & 123 & \\
\hline $36 n$ & $\begin{array}{l}\text { Poot-wo- } \\
\text { cardisel } \\
\text { Infaretion }\end{array}$ & 214 & 268 & .80 & 43 & II & 3n & .8. & 119 & $\boldsymbol{x}$ & 83 & 1.29 & 42 & 210 & .38 \\
\hline $37 n$ & $\begin{array}{l}\text { Ialopethele } \\
\text { hyperilipeade }\end{array}$ & 272 & 30 & .75 & 196 & 200 & 83 & .98 & 70 & 63 & 70 & 1.11 & 20 & 213 & .17 \\
\hline $38 \mathrm{~F}$ & Xenthan & 34 & 317 & 1.09 & 43 & 43 & 23 & 1.0 & 233 & 157 & 224 & 1.48 & 50 & 210 & .45 \\
\hline 29 & $\begin{array}{l}\text { Ephorotic } \\
\text { oypurces }\end{array}$ & $4 \pi$ & 544 & .88 & 255 & 257 & 109 & .99 & 137 & 109 & 210 & 1.26 & 78 & 155 & .50 \\
\hline 28 & Mophrotic & 1058 & 206 & .99 & 907 & 79 & 896 & 2.14 & 90 & 8 & 90 & 1.03 & 82 & 132 & .62 \\
\hline $26 x$ & $\begin{array}{l}\text { Infoetious } \\
\text { bepatitie }\end{array}$ & 169 & 328 & .52 & 30 & 59 & 32 & .51 & 132 & 208 & 212 & .63 & 9 & 56 & .16 \\
\hline $35 x$ & $\begin{array}{l}\text { Contructive } \\
\text { jevadice }\end{array}$ & 204 & 312 & .65 & 217 & 253 & or & .76 & $G$ & 88 & 68 & .76 & 23 & 66 & .20 \\
\hline $50 \mathrm{I}$ & $\begin{array}{l}\text { Pryary } \\
\text { blliery } \\
\text { elrrboels }\end{array}$ & 340 & 776 & .42 & 48 & 96 & 25 & .50 & 276 & 586 & $\infty 0$ & .47 & 13 & $\pi$ & .17 \\
\hline $57 \%$ & $\begin{array}{l}\text { Primary } \\
\text { unsery } \\
\text { efrricale }\end{array}$ & 801 & 1595 & .50 & 79 & 122 & 6 & .65 & 696 & 2432 & 261 & .49 & 11 & 82 & .14 \\
\hline
\end{tabular}


DISTRIBUTION AND COMPOSITION OF SERUM LIPOPROTEINS

TABLE V

Distribution and composition of lipoproteins in various mammals

\begin{tabular}{|c|c|c|c|c|c|c|c|c|c|c|c|c|c|c|}
\hline \multirow{2}{*}{ speec1es: } & \multicolumn{3}{|c|}{$\operatorname{serv}$} & \multicolumn{4}{|c|}{ Denality $<1.029$} & \multicolumn{4}{|c|}{ Deonesto 1.019-1.063 } & \multicolumn{3}{|c|}{ Denesity $>1.063$} \\
\hline & $\begin{array}{l}\text { Total } \\
\text { Chal. } \\
\text { (ng) }\end{array}$ & $\begin{array}{l}\text { Phoopho- } \\
\text { Ilpid } \\
100 \mathrm{nl})\end{array}$ & $\frac{x}{P L}$ & Total & $\begin{array}{l}\text { Phomplo- } \\
\text { Lidd } \\
(\mathrm{m} / 100 \mathrm{II}\end{array}$ & $\begin{array}{l}\text { Pro- } \\
\text { tedn } \\
\text { ) }\end{array}$ & $\frac{26}{50}$ & $\begin{array}{l}\text { Total } \\
\text { Chal. }\end{array}$ & $\begin{array}{l}\text { Phoopho- } \\
\text { Ifpid } \\
(100 \mathrm{nI})\end{array}$ & $\begin{array}{l}\text { Pro- } \\
\text { toln }\end{array}$ & $\frac{2 x}{2 x}$ & $\begin{array}{l}\text { Total } \\
\text { Chal. } \\
\text { (1): }\end{array}$ & $\begin{array}{l}\text { Phompo- } \\
\text { Lpid } \\
00 \mathrm{II})\end{array}$ & $\frac{x}{25}$ \\
\hline $\begin{array}{l}\text { Mean velues } \\
\text { for young } \\
\text { colut mimane }\end{array}$ & 179 & 226 & .79 & 23 & 28 & 27 & .82 & 103 & 74 & 60 & 1.39 & 49 & 123 & .40 \\
\hline Rabbet & 41 & 93 & .44 & 25 & 18 & 14 & .83 & 9 & 21 & 12 & .83 & 17 & 69 & .25 \\
\hline Bat & 50 & $W_{4}$ & .44 & 6 & 27 & 22 & .35 & 20 & 13 & 27 & .77 & 31 & 78 & .40 \\
\hline P16 & 106 & 161 & .66 & 8 & 12 & 20 & .67 & 51 & 37 & 36 & 1.4 & 41 & 102 & .40 \\
\hline Dimeter & 221 & 269 & .45 & 25 & 4 & $\boldsymbol{2}$ & .57 & $\approx$ & 34 & 22 & .85 & 61 & 276 & .35 \\
\hline Dos & 150 & 362 & .41 & 2 & 10 & 9 & .20 & 10 & 19 & 17 & .53 & 227 & 325 & .39 \\
\hline Monkey & 173 & 295 & .59 & 17 & 20 & 13 & .85 & Q. & Q & 52 & 1.0 & 80 & 206 & .39 \\
\hline
\end{tabular}

for protein were carried out on the fractions. For total cholesterol the mean values for the separately centrifuged fractions differed by no more than \pm 3 per cent; this difference was of the same order of magnitude as the maximum difference between duplicate chemical analyses. For phospholipid the fractions differed by no more than \pm 2 per cent; the difference between the duplicates was no more than \pm 1 per cent. Protein content of the separately centrifuged fractions differed by no more than \pm 1 per cent.

\section{Patients with hyperlipoproteinemia}

In Table IV are shown examples of lipoprotein distribution and composition in several diseases associated with hyperlipoproteinemia. . In the first group are patients with atherosclerosis or diseases which predispose to it; in the second group are patients with liver disease.

In the first group the concentration of the $\mathrm{D}<1.063$ fraction is increased in all patients. This increase may be entirely in the $D$ 1.0191.063 fraction, in the $D<1.019$ fraction, or in both. The $\mathrm{D}>1.063$ fraction shows no consistent pattern of variation. Thus, in the patient with idiopathic hyperlipemia the concentration increment is entirely in the $\mathrm{D}<1.019$ fraction, and the other fractions are actually decreased. In contrast the patient with xanthoma tendinosum shows a marked increase in the $D$ 1.019-1.063 fraction, very slight increase in the $D<1.019$ fraction, and normal $D>1.063$ fraction. Altera- tions in chemical composition of the fractions are also apparent. The proportion of protein to cholesterol is often altered in the two fractions in which it was measured. Cholesterol-phospholipid ratios differing from the normal are found in all fractions.

In the patients with liver disease the most consistent finding is a decrease in the lipid of the D $>1.063$ fraction. The low density fractions are uniformly increased. In these patients the separation of the two low density lipoprotein fractions was incomplete as judged by the absence of the colorless solution beneath the top layer. Hence it was necessary to choose the point of separation arbitrarily. Noteworthy are the alterations in composition of the fractions. The cholesterol-phospholipid ratios are uniformly reduced and the proportion of protein to cholesterol also varies considerably.

\section{Animals}

From Table $\mathrm{V}$ it can be seen that animals have a higher proportion of their lipid in the $D>1.063$ fraction than do humans. In some the absolute quantity of this fraction is also considerably higher than in humans. In the dog the serum total cholesterol concentration is only slightly lower than that seen in humans but almost all of it is contained in the $\mathrm{D}>1.063$ lipoproteins. In this fraction the cholesterol-phospholipid ratio is fairly constant in the various species, but it varies considerably in the other fractions. The relative 
proportion of protein in the lower density fractions also varies considerably. Of all the mammals studied only the pig closely approximates the human in distribution and composition of lipoproteins.

\section{Subfractionation of the $D>1.063$ fraction}

To a $\mathrm{D}>1.063$ fraction prepared from pooled human serum was added a quantity of solid potassium bromide sufficient to bring the non-protein solvent density to 1.125 . This solution was then subjected to ultracentrifugation in the $\mathrm{J}$ rotor of the Spinco Model E ultracentrifuge at 173,000 $\times \mathrm{G}$. for 18 hours. The supernate was removed in the usual fashion. The solvent density of the infranate was then raised to 1.21 by further addition of potassium bromide and the centrifugation and separation repeated. The chemical composition of the three fractions obtained is shown in Table VI.

TABLE VI

Distribution and composition of human serum lipoproteins of density $>1.063$

\begin{tabular}{|c|c|c|c|c|}
\hline & rotal & 1.063-1.125 & 1.125-1.2. & Donedty \\
\hline & \multicolumn{4}{|c|}{ a/100 al ont1ve cerce } \\
\hline chalostartorol & 35 & 14 & 20 & $<2$ \\
\hline $\begin{array}{l}\text { Foopho- } \\
\text { 11pie }\end{array}$ & 101 & 26 & 43 & 27 \\
\hline Protain & -. & 39 & 87 & -- \\
\hline$\frac{\pi}{x}$ & .35 & .50 & .47 & $<.1$ \\
\hline$\frac{x}{\cos x \sin }$ & -. & .36 & .23 & -. \\
\hline
\end{tabular}

It is evident that cholesterol and lipid phosphorus are present in the 2 fractions of $D<1.21$. Their chemical composition differs only in the higher protein content of the D 1.125-1.21 fraction. The D $>1.21$ fraction contains lipid phosphorus but practically no cholesterol. Ethanol-acetone soluble phosphorus has been found repeatedly in 1.21 infranates, both from pooled serum and fresh serum, whether centrifuged initially at density 1.21 or following preliminary flotation at lower densities. Further, no difference has been observed whether flotation was carried out in the 40 rotor for 48 hours, the 40.3 rotor for 23 hours, or the $\mathrm{J}$ rotor for 18 hours. In six young adults the 1.21 density infranate contained 15 to $27 \mathrm{mg}$. per $100 \mathrm{ml}$. of the serum phospholipids, and in
TABLE VII

Comparison of lipoprotein values in young adults obtained by various methods

\begin{tabular}{|c|c|c|c|c|c|c|}
\hline \multirow{2}{*}{$\begin{array}{l}\text { Metbod of } \\
\text { naelyese }\end{array}$} & \multicolumn{2}{|c|}{ Denasty $<1.019$} & \multicolumn{2}{|c|}{ Deanity 1.019-1.063 } & \multicolumn{2}{|c|}{ Deanity >1.063 } \\
\hline & mese & nonelo & me & Penes & mese & nome \\
\hline & \multicolumn{6}{|c|}{ ad/100 al eere or placen } \\
\hline Mrecent. & 270 & 130 & 320 & 360 & 340 & 430 \\
\hline 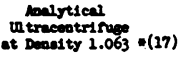 & 179 & 107 & 303 & 204 & $\cdots$ & - \\
\hline at Deanity 1.21 (19) & $\cdots$ & $\cdots$ & 200 & 260 & 15h & 183 \\
\hline Mrecticonation \& (3) & ... & $\ldots$ & $\ldots$ & $\cdots$ & 360 & 460 \\
\hline
\end{tabular}

* Age group 20-30.

Age group 18-35.

@ Bloor cholesterol multiplied by 0.9 prior to conversion to lipoprotein.

eight hyperlipoproteinemic individuals, 13 to 25 mg. per $100 \mathrm{ml}$. In all instances, total cholesterol concentration invariably has been less than $3 \mathrm{mg}$. per $100 \mathrm{ml}$. of serum by the method of Abell, Levy, Brodie, and Kendall (15) and usually zero by the Sperry-Schoenheimer method. Thus, it may be that this Liebermann-Burchard reactive substance is not cholesterol. This fraction has been further characterized in the following ways. The lipid phosphorus in 1.21 density infranates fails to float at density 1.30 following centrifugation at $173,000 \times \mathrm{G}$. for 18 hours. It is not dialyzable against $0.15 \mathrm{M}$ sodium chloride and is precipitated with the serum proteins by zinc hydroxide. In starch electrophoresis the bulk of the lipid phosphorus migrates with the alpha ${ }_{1}$-albumin fraction, the remainder trailing with the other globulin fractions. ${ }^{2}$

\section{DISCUSSION}

In Table VII serum lipoprotein concentrations obtained by this method are compared with values obtained by other methods. For our data and for those of Russ, Eder, and Barr (3), lipoprotein concentrations have been calculated from the cholesterol values by utilizing the known cholesterol contents of lipoprotein fractions isolated from pooled human serum. These values are: $\mathrm{D}<1.019$, 15 per cent; D 1.019-1.063, 30 per cent; and D 1.063-1.21, 12.5 per cent (16). The

$2 \mathrm{We}$ are indebted to Dr. Henry G. Kunkel of the Rockefeller Institute for Medical Research for performing this analysis. 
$\mathrm{D}<1.019$ fraction corresponds roughly to the Gofman $S_{t} 12-400$ class, the D 1.019-1.063 fraction corresponds to the Gofman $S_{\mathrm{f}} 0-12$ class and the Lewis - S 25-40 class, and the $\mathrm{D}>1.063$ fraction corresponds to the Lewis - S 1-10 class and Cohn fraction IV + V + VI.

It is evident that there is good agreement with the data published by Gofman, Glazier, Tamplin, Strisower, and deLalla (17) except for the D 1.019-1.063 fraction in women. This may be due to the small size of our sample. Recently, preliminary results of high density lipoprotein analysis have been published by the Donner Laboratory group (18) and these also appear to give values similar to our $\mathrm{D}>1.063$ fraction. The data of Lewis and Page (19) differ greatly from our data and from the data of others. In our hands their method of preparative ultracentrifugation fails to float all the cholesterol. This would account in part for their lower results. Our data agree well with the data of Russ, Eder, and Barr (3) obtained by Cohn fractionation. Not shown in the table is the comparison of our $\mathrm{D}<1.063$ fraction with their fraction I + III. Our mean value for total cholesterol in this fraction is 120 mg. per $100 \mathrm{ml}$. as compared to their value of 125 . The cholesterol-phospholipid ratios obtained by these two methods also agree closely. Data obtained by zone electrophoresis $(4-6)$ also agree closely with our data.

The observations on the patients with diseases predisposing to atherosclerosis confirm and extend those of McGinley, Jones, and Gofman (20) who found that hyperlipoproteinemia may involve the $\mathrm{D}<1.063$ flotation fractions to a variable degree. While the number of patients is small it is of interest that the cholesterol in the $D>1.063$ fraction is reduced in only one of the patients having diseases predisposing to atherosclerosis as contrasted to the finding of Barr, Russ, and Eder (21) that cholesterol in Cohn fraction IV + V + VI was usually markedly reduced. This apparent discrepancy requires further investigation.

The results obtained in patients with liver disease corroborate previous observations $(4,5,9)$ regarding the marked lowering of the alpha lipoproteins in obstructive jaundice. Eder, Russ, Pritchett, Wilber, and Barr (9) also found alterations in the chemical composition of the low den- sity lipoproteins. Our data further show that this alteration involves both subfractions of this group. Since "pure" lipoproteins were not isolated by this procedure, it is apparent that these alterations in composition may possibly reflect changes in the proportions of different lipoproteins contained in the fractions. The altered chemical composition of the D 1.019-1.063 fraction could well account for its increased mean flotation rate in the analytical ultracentrifuge (22) and its poor resolution at density 1.019 from the lower density lipoproteins in the preparative ultracentrifuge.

The data further illustrate the complex nature of the cholesterol-phospholipid ratio of whole serum. Since in normocholesterolemic individuals the ratio in the $\mathrm{D}<1.019$ fraction is similar to that of serum, alterations in the concentration of this component will not appreciably alter the whole serum ratio. On the other hand, since the ratios in the $D$ 1.019-1.063 and $D>1.063$ fractions are appreciably different from the serum value, changes in the proportions of these components could alter the serum ratio significantly. Equally important, however, in determining the cholesterol-phospholipid ratio in serum are the

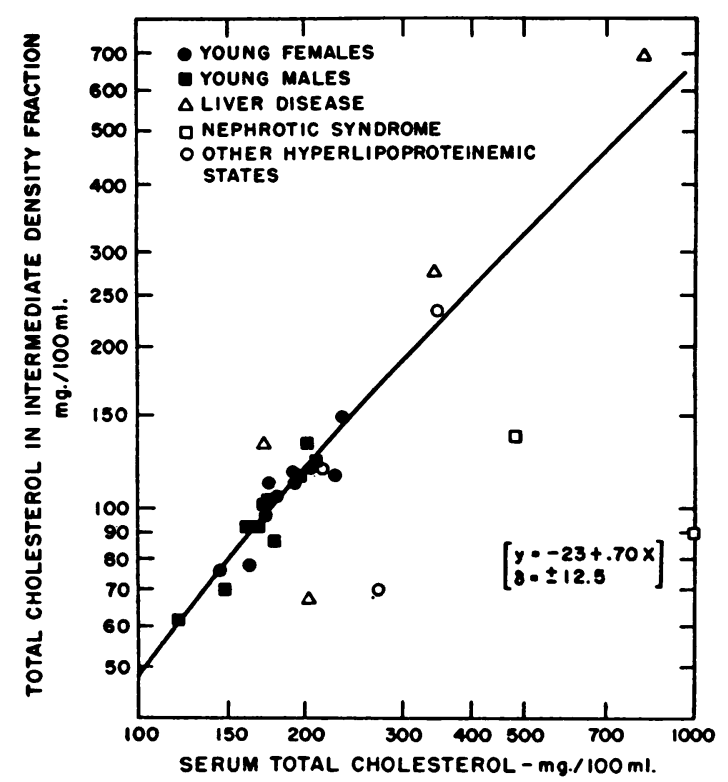

Fig. 1. Relation of Total Cholesterol in D 1.0191.063 Fraction to Serum Total Cholesterol

Regression line was calculated from data on 10 young females and 10 young males by method of least squares. $\delta=$ standard deviation from regression. 
alterations in lipoprotein composition of the fractions that occur with disease.

In Figure 1 is shown the correlation between the serum total cholesterol and the total cholesterol in the D 1.019-1.063 fraction in young adults and in the patients with hyperlipoproteinemia. As could be predicted $a$ priori this correlation is good in young adults, since the D 1.019-1.063 fraction is the major cholesterol-containing component. The figure also shows that it is not possible to apply this correlation to the prediction of D 1.019 1.063 lipoprotein concentration from the serum total cholesterol in hyperlipoproteinemic states. In only two of the nine hyperlipoproteinemic subjects does the cholesterol in the D 1.019-1.063 fraction fall within one standard deviation of the regression line calculated for young adults. The correlation between the total cholesterol in the other fractions and the serum total cholesterol is poor. Likewise, intercorrelations between the total cholesterol contents of the various fractions are poor.

Study of the lipoproteins of D 1.063-1.21 shows, in agreement with observations of deLalla and Gofman (7), that these consist of more than one density class. The protein analysis shows that the different flotation classes also differ in chemical composition. The lipid phosphorus found in the $\mathrm{D}>1.21$ fraction is of special interest; its behavior makes it likely that it is contained in a lipoprotein, but it is unique in that it contains virtually no cholesterol. Turner, Snavely, Goldwater, and Randolph, on the basis of chemical analyses of incompletely separated lipoprotein fractions in the ultracentrifuge, have calculated that a phospholipid-containing, cholesterol-free lipoprotein accounts for about 60 per cent of the serum phospholipid (23). Our data suggest that such a lipoprotein can account for no more than 15 per cent of the total serum phospholipid. Since the quantity of lipid phosphorus in the $\mathrm{D}>1.21$ fraction appears to be relatively constant, even in disease, a decrease in the other high density lipoproteins would result in a lower cholesterol-phospholipid ratio in the $D>1.063$ fraction. Low cholesterol-phospholipid ratios in the $\mathrm{D}>1.063$ fraction are seen in the five hyperlipoproteinemic individuals with low concentrations of cholesterol in this fraction (Table III).

\section{SUMMARY}

1. A method for the analysis of serum lipoproteins is described. Lipoprotein fractions are isolated by repeated ultracentrifugations after progressively raising the solvent density. The separated fractions are characterized by lipid and protein analysis. It is possible to separate several lipoprotein fractions from the same serum sample. Routinely three fractions of densities $<1.019$, $1.019-1.063$, and $>1.063$ have been analyzed. The accuracy of the procedure is limited by the accuracy of the chemical methods employed.

2. Data obtained in young adults demonstrate that approximately two-thirds of the serum cholesterol and half the lipid phosphorus are contained in the density $1.019-1.063$ fraction. The quantity of lipid is greater in the density $<1.019$ fraction and less in the density $>1.063$ fraction in young men as compared with young women. The ratio of total cholesterol to phospholipid is similar to that of serum in the density $<1.019$ fraction, considerably greater in the density 1.0191.063 fraction, and considerably less in the density $>1.063$ fraction.

3. In disease hyperlipoproteinemia involves one or both of the two lower density fractions. The density $>1.063$ fraction is variably affected; in biliary obstruction it is markedly reduced. Alterations in composition of the lipoprotein fractions also occur; these are most striking in biliary obstruction.

4. In animal sera wide variations in the distribution and composition of lipoproteins occur. A greater proportion of the lipid is associated with the density $>1.063$ fraction than in man.

5. Subfractionation of the density $>1.063$ fraction demonstrates two fractions containing cholesterol and lipid phosphorus of densities 1.0631.125 and 1.125-1.21. The fraction of density $>1.21$ contains 10 to 15 per cent of the serum lipid phosphorus but practically no cholesterol. This phosphorus is non-dialyzable and migrates with the alpha ${ }_{1}$-albumin fraction in starch electrophoresis (see addendum).

\section{Addendum}

Since this paper was submitted for publication it has been reported by Hack that about 10 per cent of the phosphorus extracted from human serum with ethanolether is insoluble in petroleum ether and can be ac- 
counted for by a peptide containing serine phosphate, threonine, and glutamic acid (Federation Proc., 1955, 14, 222). We have found that the zinc hydroxide precipitable, ethanol-acetone soluble phosphorus in 1.21 density infranates is completely water soluble and insoluble in petroleum ether. The amino acids serine, threonine, glutamic acid, glycine, alanine, and leucine or isoleucine have been found in acid hydrolysates of the water soluble fraction. Further work on the nature of the phosphate in this fraction is in progress.

\section{REFERENCES}

1. Lindgren, F. T., Elliott, H. A., and Gofman, J. W., The ultracentrifugal characterization and isolation of human blood lipids and lipoproteins, with applications to the study of atherosclerosis. J. Phys. \& Colloid Chem., 1951, 55, 80.

2. Cohn, E. J., Gurd, F. R. N., Surgenor, D. M., Barnes, B. A., Brown, R. K., Derouaux, G., Gillespie, J. M., Kahnt, F. W., Lever, W. F., Liu, C. H., Mittelman, D., Mouton, R. F., Schmid, K., and Uroma, E., A system for the separation of the components of human blood: Quantitative procedures for the separation of the protein components of human plasma. J. Am. Chem. Soc., 1950, 72, 465.

3. Russ, E. M., Eder, H. A., and Barr, D. P., Proteinlipid relationships in human plasma. I. In normal individuals. Am. J. Med., 1951, 11, 468.

4. Swahn, B., Studies on blood lipids. Scandinav. J. Clin. \& Lab. Invest., 1953, 5, suppl. 9.

5. Kunkel, H. G., and Slater, R. J., Lipoprotein patterns of serum obtained by zone electrophoresis. J. Clin. Invest., 1952, 31, 677.

6. Nikkilä, E., Studies on the lipid-protein relationship in normal and pathological sera and the effect of heparin on serum lipoproteins. Scandinav. J. Clin. \& Lab. Invest., 1953, 5, suppl. 8.

7. deLalla, O. F., and Gofman, J. W., Ultracentrifugal analysis of serum lipoproteins In Methods of Biochemical Analysis, New York, Interscience, 1954, vol. 1, p. 459.

8. Lewis, L. A., Green, A. A., and Page, I. H., Ultracentrifuge lipoprotein pattern of serum of normal, hypertensive and hypothyroid animals. Am. J. Physiol., 1952, 171, 391.

9. Eder, H. A., Russ, E. M., Pritchett, R. A. R., Wilber, M. M., and Barr, D. P., Protein-lipid relationships in human plasma: In biliary cirrhosis, obstructive jaundice, and acute hepatitis. J. Clin. Invest., 1955, 34, 1147.
10. Turner, R. H., Snavely, J. R., Goldwater, W. H., Randolph, M. L., Sprague, C. C., and Unglaub, W. G., The study of serum proteins and lipids with the aid of the quantity ultracentrifuge. I. Procedure and principal features of the centrifugate of untreated normal serum as determined by quantitative analysis of samples from ten levels. J. Clin. Invest., 1951, 30, 1071.

11. Randolph, M. L., and Ryan, R. R., A slicer for sampling liquids. Science, 1950, 112, 528.

12. Sperry, W. M., and Webb, M., A revision of the Schoenheimer-Sperry method for cholesterol determination. J. Biol. Chem., 1950, 187, 97.

13. Stewart, C. P., and Hendry, E. B., The phospholipins of blood. Biochem. J., 1935, 29, 1683.

14. Gornall, A. G., Bardawill, C. J., and David, M. M., Determination of serum proteins by means of the biuret reaction. J. Biol. Chem., 1949, 177, 751.

15. Abell, L. L., Levy, B. B., Brodie, B. B., and Kendall, F. E., A simplified method for the estimation of total cholesterol in serum and demonstration of its specificity. J. Biol. Chem., 1952, 195, 357.

16. Unpublished data.

17. Gofman, J. W., Glazier, F., Tamplin, A., Strisower, B., and deLalla, O., Lipoproteins, coronary heart disease, and atherosclerosis. Physiol. Rev., 1954, 34, 589.

18. Rubin, L., and Aladjem, F., Serum lipoprotein changes during fasting in man. Am. J. Physiol., 1954, 178, 263.

19. Lewis, L. A., and Page, I. H., Electrophoretic and ultracentrifugal analysis of serum lipoproteins of normal, nephrotic and hypertensive persons. Circulation, 1953, 7, 707.

20. McGinley, J., Jones, H., and Gofman, J., Lipoproteins and xanthomatous diseases. J. Invest. Dermat., 1952, 19, 71.

21. Barr, D. P., Russ, E. M., and Eder, H. A., Protein-lipid relationships in human plasma. II. In atherosclerosis and related conditions. Am. J. Med., 1951, 11, 480.

22. Pierce, F. T., Jr., Kimmel, J. R., and Burns, T. W., Lipoproteins in infectious and serum hepatitis. Metabolism, 1954, 3, 228.

23. Turner, R. H., Snavely, J. R., Goldwater, W. H., and Randolph, M. L., The study of serum proteins and lipids with the aid of the quantity ultracentrifuge. VII. Some features of a system of lipoproteins which contain phospholipid but no free cholesterol. Yale J. Biol. \& Med., 1952, 24, 450. 